\title{
Shifting policy towards a cavity-free future
}

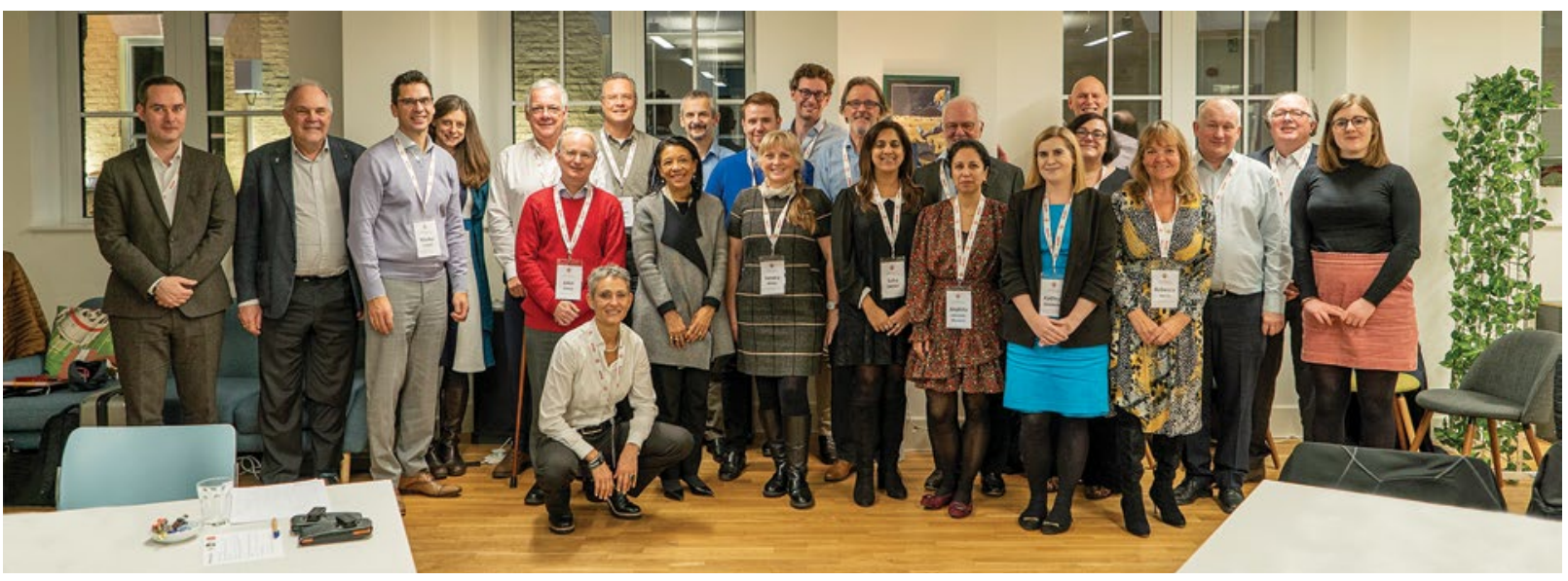

Members of the King's College London/ACFF Dental Policy Lab Network

King's College London researchers studying dental caries and their international partners have been working as, and with, the Alliance for a Cavity-Free Future (ACFF, a King's-led dental charity with global reach, chaired by Professor Nigel Pitts) and in collaboration with the Policy Institute at King's, using their 'Policy Lab methodology', developed a series of three very successful 'Dental Policy Labs'.

The Dental Policy Lab has been a successful, dynamic initiative first launched in 2017 and each time has brought together a diverse group of international experts, challenging them with solving a pressing global issue within both clinical practice and public health over a 24-hour period. Previous Dental Policy Labs have explored and addressed significant questions and have had immediate impacts on international health policy. For example, the 2017/18 Labs saw the French National Health Service (Assurance Maladie), the ICDAS/ICCMS Group and the FDI Chief Dental Officers/
Dental Public Health Section taking action based on the Lab's findings.

The latest report has now been published. Its title is 'Towards Oral and Dental Health through Partnership: How can the oral health and dental industries benefit from enabling positive behaviour in caries prevention and control amongst patients and the public?' which captures the overarching policy question addressed by the Lab.

The report details the discussions and findings of the third and final Dental Policy Lab, lists the broad range of internationally influential academics and industry experts, and provides a strategy for implementing the findings of not only this Lab, but the outputs of all three through the new 'King's College London/ACFF Dental Policy Lab Network'.

Professor Nigel Pitts, Chair of ACFF Global, said that: 'The third Dental Policy Lab was unique and exciting and brought together a range of people who do not normally have the opportunity to collaborate.
Professor John Girkin (Durham University and NirVisio Ltd.), a participant of the Dental Policy Lab, echoed this, confirming that 'Getting together the large range of people that are in this Lab, from the people at the top of public health through to the people that are at the top of the companies through to the people like me that invent things, and bringing them all in the same room at the same time and hearing different people's perspectives, this is a huge benefit'.

Each Lab has seen enthusiastic 'buy-in' from all delegates, and this keenness was once again shown by attendees at the latest Lab, particularly in forming the new King's College London/ACFF Dental Policy Lab Network in order to drive forward the plan of advancing the four key areas (identified in the report's summary) in collaboration with the King's Global Collaboratory for Caries Management, with the end goal of achieving a cavity-free future worldwide.

The Dental Policy Lab 3 full report can be viewed here: https://bit.ly/2Vn71xw.

\section{$B D J$ offers support to dental companies}

Paul Darragh, Account Executive for the BDJ Portfolio, has invited dental companies and manufacturers to submit a free entry for the

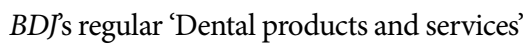
section during the coronavirus crisis.

Paul said: 'We are undoubtedly experiencing the most challenging of times. Our wonderful industry is feeling the full force of the COVID-19 pandemic with thousands of dental practices across the UK closing their doors, meaning that dentists and their practice teams can't do the amazing job that they do.

'Understandably, product sales will take a hit but I want to reassure you that the $B D J$ is here to help support you during these tough times.'

The $B D J$ will continue to be delivered to every British Dental Association (BDA) member - all 17,000 of them - delivering the quality, engaging clinical content that they expect from their journal.
To take up the offer of a free slot in the $B D$ 's Dental products and services section, just email Paul approximately 250 words and an image of your product. We will then publish this for you in the next available issue [subject to space], and it will also appear indefinitely on the $B D$ 's website.

To contact Paul, email paul.darragh@ springernature.com or call 02070144122 or 07725218506 . 